\title{
GRAPHICAL ANALYSIS OF PERFORMANCE OF A VIBRATORY BOWL FEEDER FOR FEEDING BUTTONS
}

\author{
Shaine Ansari ${ }^{1}$, Loveleen Gautam ${ }^{2}$, Pradeep Khanna ${ }^{3}$ \\ ${ }^{I}$ Student, Department of MPAE, Netaji Subhas Institute of Technology, New Delhi \\ ${ }^{2}$ Student, Department of MPAE, Netaji Subhas Institute of Technology, New Delhi \\ ${ }^{3}$ Associate Professor, Department of MPAE, Netaji Subhas Institute of Technology, New Delhi
}

\begin{abstract}
Automation of manufacturing industry has now become an integral part of industry as it is capable of delivering products in right quantity, quality and consistency. There are many aspects of industrial automation depending upon the type of product and the industry. One such aspect is assembly line which streamlines the flow of product from one assembly station to the other in predecided cycle time to cater to the needs of assembly line many a times discrete part feeding in required quantity and in desired orientation becomes indispensable. This task can successfully be done with the help of a suitable feeding mechanism. Vibratory bowl feeder has been a choice of industry for its versatility. The present study is aimed at analysing the performance of a vibratory bowl feeder with different size of buttons in garment fabrication industry. The desired outcome in this case is the feed rate and the various input parameters for the study are - part population, part size and frequency of bowl. A number of experiments have been conducted and the outcomes are graphically analysed to predict the performance behaviour of the feeder.
\end{abstract}

Keywords: - Automation, Feeder, Cycle time, Feed rate, Graphical Analysis.

$$
* * *
$$

\section{INTRODUCTION}

A feeder is a machine used to feed or load any kind of material, chemical or product to the assembly line, manufacturing stations or wherever necessary. It is specifically used to feed material one by one at any desired rate. Process equipment manufacturers have developed a vast body expertise and a wide range of feed technology so as to efficiently meet the different requirements of feeding for different industries. [1]

The feeder selection is a key in success related to achieve desired feeding. Hence, different types of Feeders have been made to cater to different kinds of feeding requirement which are: [2]

1. Centrifugal Feeder

2. Vibratory Feeder

3. Linear Feeder

4. Flex Feeder

5. Step Feeder

6. Elevator Feeder

The feeder used during this experiment is Vibratory Bowl Feeder. It is an instrument that uses vibration to feed material. It uses both vibration and gravity to move materials. Gravity is used to determine the direction, either down, or down and to a side, and then vibration is used to move the materials. They are mainly used to transport a large number of smaller objects. [3] We have opted this feeder for our experiment because it is an easy to use and high performing part feeding machine. Apart from that, it has lower error rates, less power consumption, better profits, better rates of efficiency and less dependency on man power. [4]

\section{LITERATURE SURVEY}

A number of research papers have been surveyed to understand the importance of mechanized feeding and the various techniques used by the experimenters to analyse the behaviour of these feeders. According to Chauhan et. al. [5], factorial approach to study the effects of various parameters on vibratory bowl feeder gives satisfactory results.

Bhagat et. al. [6 \& 7], conducted graphical as well as mathematical analysis on the performance of vibratory bowl feeder for feeding headed components and concluded that the developed model not only was able to estimate the magnitude and direction of the effects of change in factors but also predicts the effects of their mutual interactions.

Jindal et. al. [8 \& 9] carried out experimentation, graphical as well as mathematical, with vibratory bowl feeder on clip shaped components and observed that the maximum feed rate is obtained for highest part population and at the highest frequency and for the smallest part size in graphical analysis. Whereas mathematical model along with interaction study revealed that part length was least significant a factor.

Jain et. al. [10] applied Taguchi approach in optimizing the performance of vibratory bowl feeder and found that Frequency has a positive effect on feed rate whereas part population has a negative effect on feed rate. Initially the 
effect of part size is negative but it becomes positive after a while due to its interaction with frequency and part population.

\section{EXPERIMENTAL SETUP}

The experimental setup used for conducting the experiments is shown in figure 1. It consisted of a vibratory bowl feeder having bowl diameter of $300 \mathrm{~mm}$. The unit as a frequency selecting unit which facilitates stepless control of frequency of vibrations that acts as an important factor affecting the feed rate of this feeder. Arrangement was made to prevent multiple feeding of components as far as possible. The components selected for the experiments were circular buttons with 3 different sizes viz. $16 \mathrm{~mm}, 21 \mathrm{~mm}$ and $26 \mathrm{~mm}$ respectively. A number of trial experiments were conducted to identify important input parameters and their operating ranges. As shown in table-1

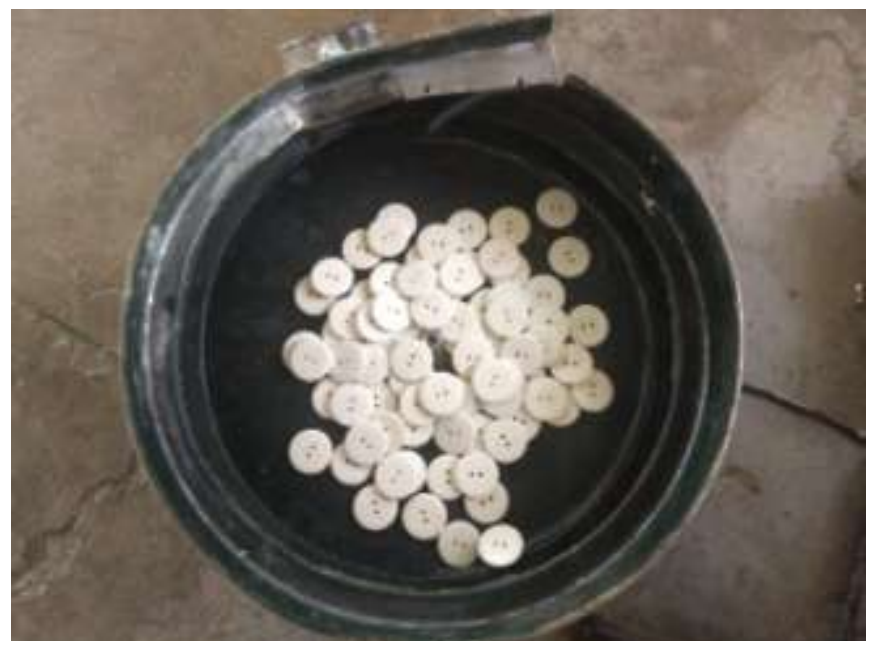

Fig 1: The experimental set up
Table 1: Input parameters and their operating limits

\begin{tabular}{|l|l|l|l|}
\hline PARAMETERS & UNIT & $\begin{array}{l}\text { LOWER } \\
\text { LIMIT }\end{array}$ & $\begin{array}{l}\text { UPPER } \\
\text { LIMIT }\end{array}$ \\
\hline FREQUENCY & $\mathrm{Hz}$ & 35 & 45 \\
\hline PART SIZE & $\mathrm{Mm}$ & 16 & 26 \\
\hline $\begin{array}{l}\text { PART } \\
\text { POPULATION }\end{array}$ & No. & 100 & 200 \\
\hline
\end{tabular}

\section{CONDUCTING THE EXPERIMENTS}

There were 3 parameters used and analysis was done by using OFAT (One factor at a time). Thus, by keeping 2 factors constant and by varying the third one readings were taken. Hence, all the 3 parameters were varied one by one and we obtained a total of 27 readings. The experiments were conducted by using one factor at a time technique though the technique does not entertain the interaction effects among the parameters and hence limiting its applicability but still it can give an approximation of the performance behaviour of the unit and the study can be used as a preliminary stage to further conduct elaborated analysis on the unit. Experiments were conducted by varying only one parameter at a time keeping the other two parameters constant. Input parameters were varied at three levels namely lowest, intermediate and highest. Each observation was performed in three replicates totalling 27 observations. As shown in table 2.

Table 2: Experimental observations

\begin{tabular}{|c|c|c|c|c|c|c|}
\hline PART SIZE & $\begin{array}{l}\text { PART } \\
\text { POPULATION }\end{array}$ & FREQUENCY & \multicolumn{3}{|c|}{ FEED RATE (PARTS/MIN) } & $\begin{array}{l}\text { MEAN FEED } \\
\text { RATE }\end{array}$ \\
\hline 16 & 100 & 35 & 13 & 15 & 14 & 14 \\
\hline 16 & 100 & 40 & 61 & 63 & 70 & 65 \\
\hline 16 & 100 & 45 & 102 & 112 & 113 & 109 \\
\hline 16 & 150 & 35 & 41 & 34 & 32 & 36 \\
\hline 16 & 150 & 40 & 66 & 67 & 69 & 67 \\
\hline 16 & 150 & 45 & 177 & 160 & 156 & 164 \\
\hline 16 & 200 & 35 & 43 & 47 & 50 & 47 \\
\hline 16 & 200 & 40 & 67 & 75 & 84 & 75 \\
\hline 16 & 200 & 45 & 246 & 247 & 254 & 249 \\
\hline 21 & 100 & 35 & 11 & 12 & 15 & 13 \\
\hline 21 & 100 & 40 & 63 & 71 & 72 & 69 \\
\hline 21 & 100 & 45 & 132 & 147 & 150 & 143 \\
\hline 21 & 150 & 35 & 20 & 20 & 17 & 19 \\
\hline 21 & 150 & 40 & 85 & 86 & 88 & 86 \\
\hline 21 & 150 & 45 & 155 & 155 & 160 & 156 \\
\hline 21 & 200 & 35 & 37 & 41 & 47 & 42 \\
\hline 21 & 200 & 40 & 61 & 63 & 69 & 64 \\
\hline
\end{tabular}




\begin{tabular}{|l|l|l|l|l|l|l|}
\hline 21 & 200 & 45 & 228 & 238 & 240 & 235 \\
\hline 26 & 100 & 35 & 14 & 18 & 22 & 18 \\
\hline 26 & 100 & 40 & 92 & 93 & 97 & 94 \\
\hline 26 & 100 & 45 & 107 & 108 & 116 & 110 \\
\hline 26 & 150 & 35 & 51 & 56 & 74 & 60 \\
\hline 26 & 150 & 40 & 98 & 116 & 126 & 113 \\
\hline 26 & 150 & 45 & 140 & 154 & 167 & 154 \\
\hline 26 & 200 & 35 & 34 & 36 & 42 & 37 \\
\hline 26 & 200 & 40 & 110 & 126 & 129 & 122 \\
\hline 26 & 200 & 45 & 186 & 198 & 201 & 195 \\
\hline
\end{tabular}

\section{RESULTS AND DISCUSSION}

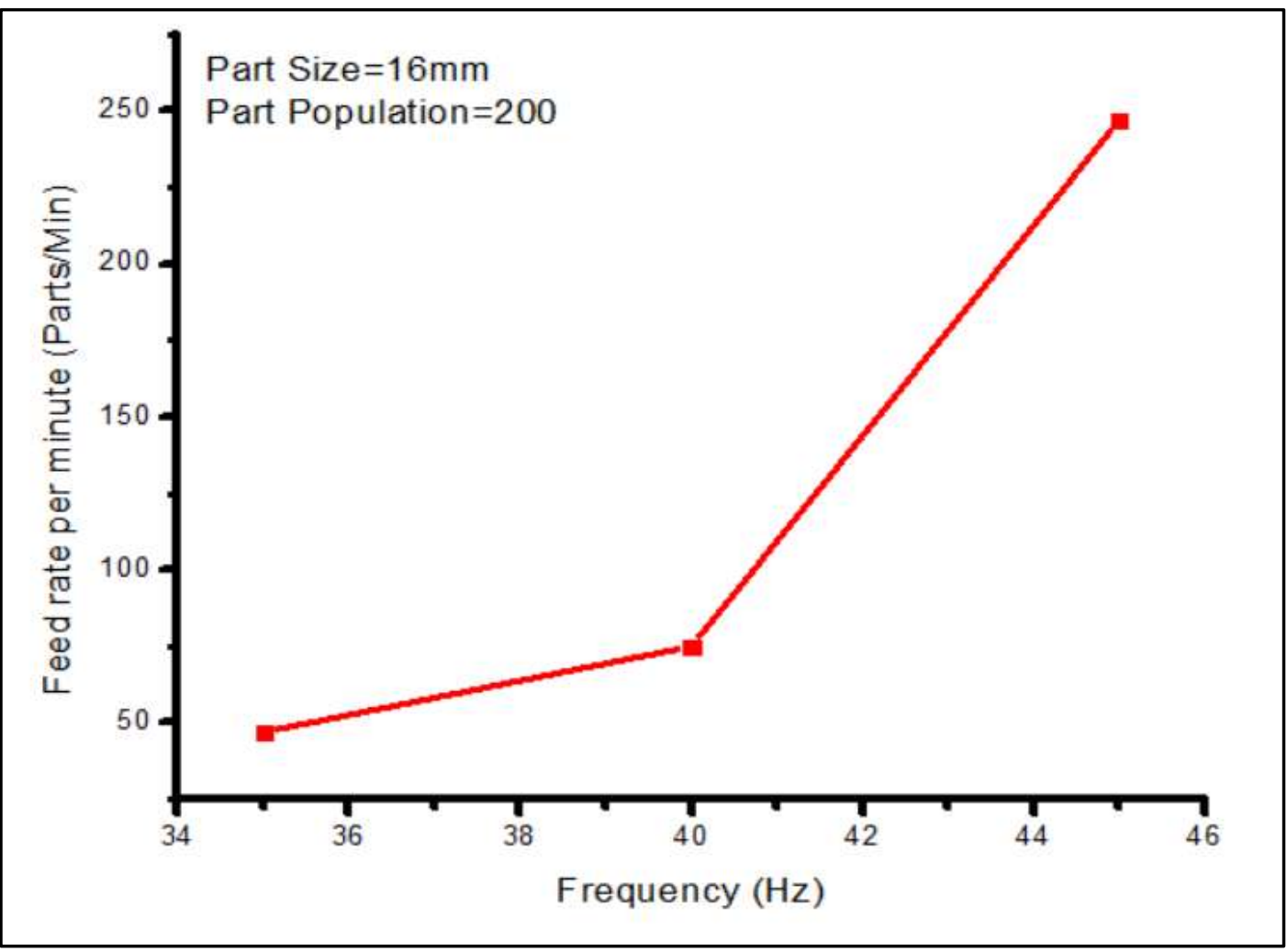

Fig 2: Effect of frequency on feed rate

Figure 2 shows the relation of feed rate per minute and frequency. It is clearly visible that with increase in frequency, there is also an increase in feed rate of the buttons per minute. The increase in feed rate for $40 \mathrm{~Hz}$ to $45 \mathrm{~Hz}$ is quite high when compared to the increase obtained in $35 \mathrm{~Hz}$ to $40 \mathrm{~Hz}$. The probable reason for this increase could be the increased agitation of the buttons about its mean position at higher frequency, due to which at higher frequency, they push each other with greater force and thus resulting in increment of feed rate.

Figure 3 shows the relation of feed rate per minute and part size. It is clearly visible from the graph that with increase in Part Size, there is a decrease Feed Rate per Min. It is also seen that the decrease in Feed Rate between Part Size $21 \mathrm{~mm}$ to $26 \mathrm{~mm}$ is quite high when compared to decrease in feed rate between $16 \mathrm{~mm}$ to $21 \mathrm{~mm}$.It could be mainly because of the decreased agitation of the buttons due to the increase in Part Size which makes it difficult for the buttons to move back and forth about its mean position. Thus, decrease in pushing force of the buttons and thereby reducing Feed Rate. 


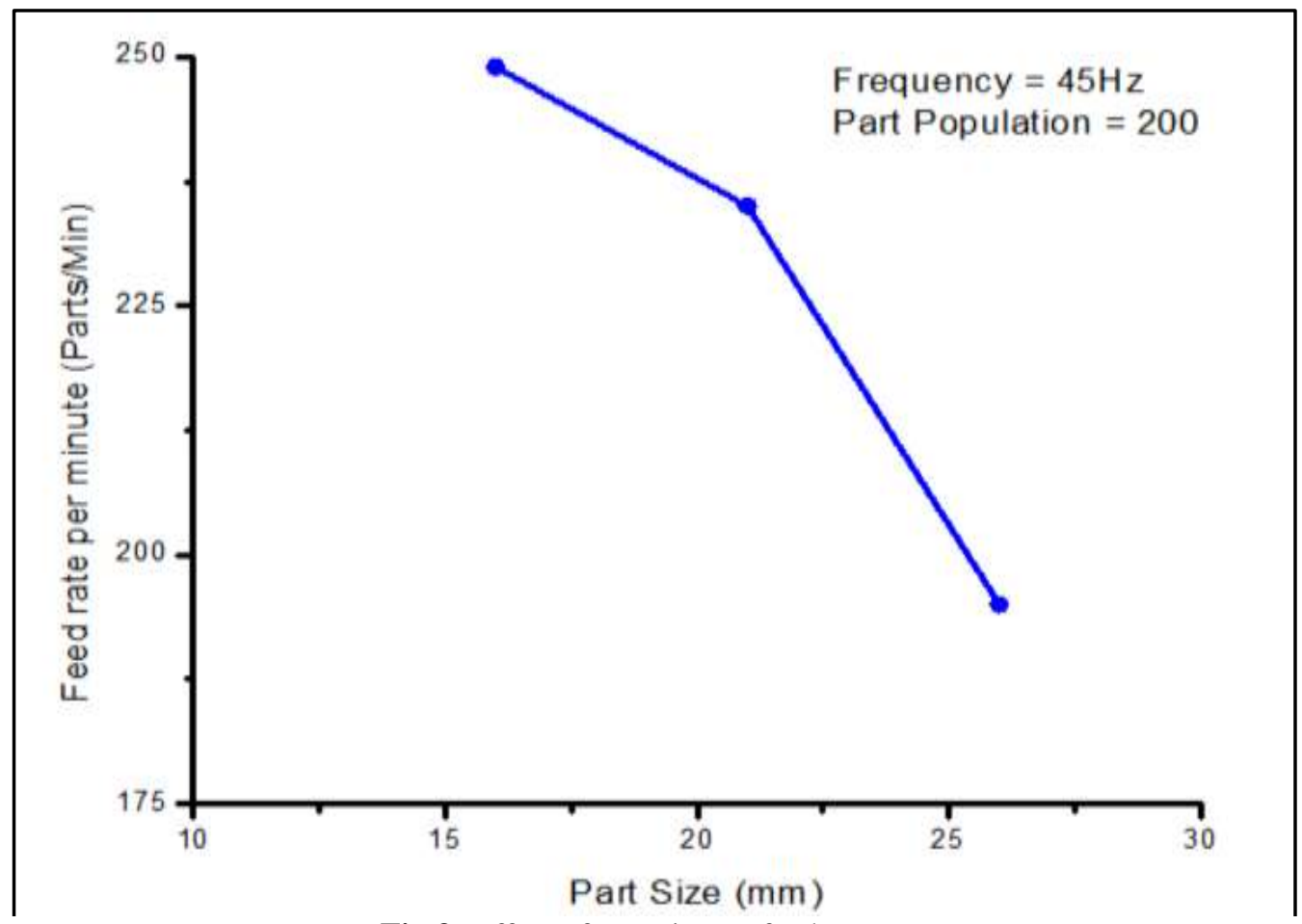

Fig 3: Effect of part size on feed rate

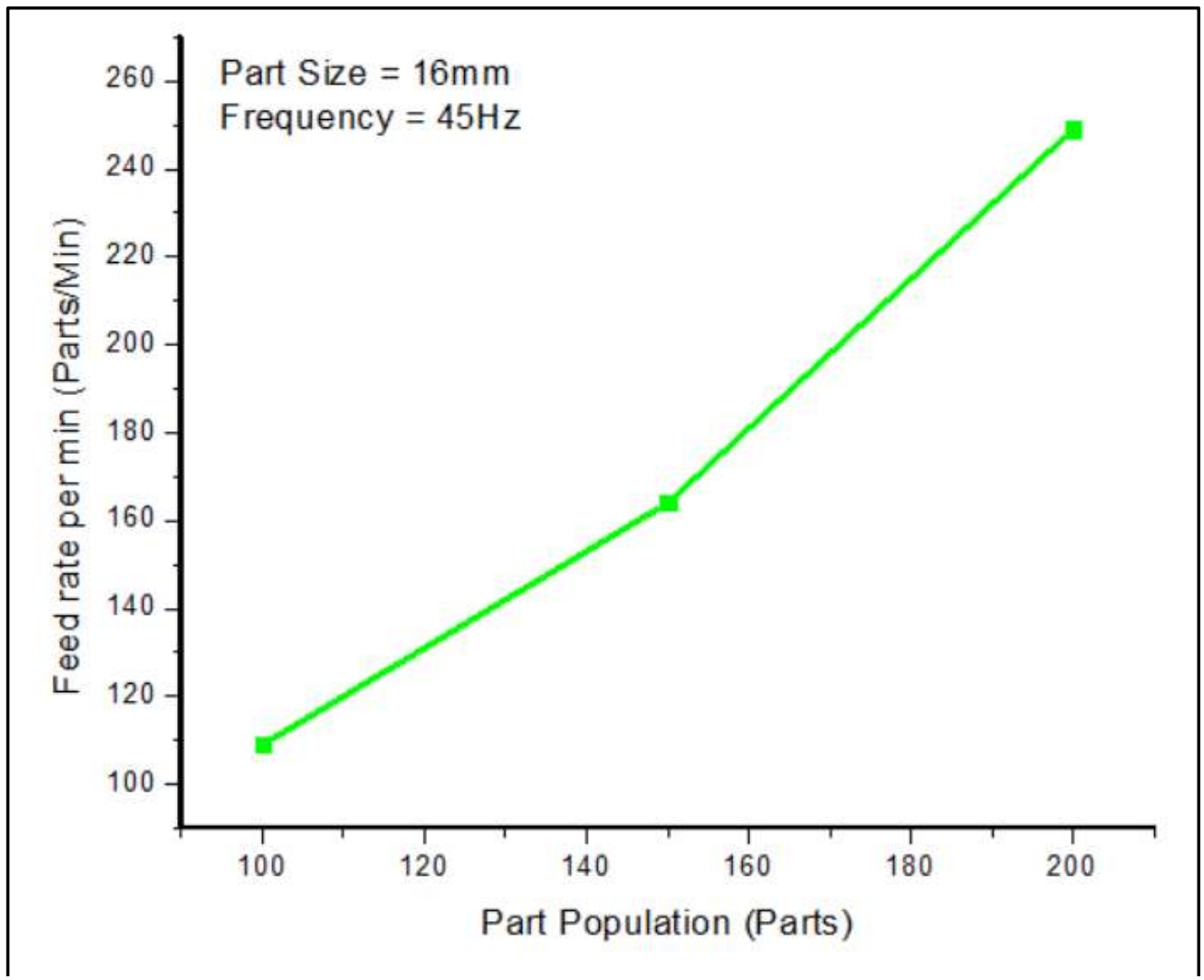

Fig 4: Effect of part population on feed rate

Figure 4 shows the relation of feed rate per minute and part population. it is visible from the graph that with the increase in part population, feed rate is also increased. the increase in feed rate with the increase in part population is linear in nature. this is probably due to the increase in the opportunity inside the feeder which gives us increased feed rate. 


\section{CONCLUSION}

The graphical analysis of the experimentation conducted show that maximum feed rate of $249 \mathrm{parts} / \mathrm{min}$ is obtained at part population of 200 , frequency $45 \mathrm{~Hz}$ and part size 16 $\mathrm{mm}$.

\section{ACKNOWLEDGEMENT}

The authors would like to thank Mr Pradeep Khanna, Associate Professor, Division of Manufacturing Processes and Automation, Netaji Subhas Institute of Technology, without whose guidance and timely support, this paper and the complete experiment would not have been possible.

\section{REFERENCES}

[1] Slide no. $\quad$ https://www.slideshare.net/faugee/feeder-equipment, accessed on 12 June, 2018.

[2] http://www.hoosierfeedercompany.com/vibratoryrotary-feeder-insights/what-are-the-different-typesof-parts-feeder-systems, accessed on 12 June, 2018.

[3] https://googleweblight.com/i?u=https://en.m.wikipedi a.org/wiki/Vibrating_feeder\&hl=en-IN\&tg=126, accessed on 12 June, 2018.

[4] https://googleweblight.com/i?u=https://en.m.wikipedi a.org/wiki/Vibrating_feeder\&hl=en-IN\&tg=126, accessed on 12 June, 2018.

[5] Chauhan, A., Nirman, G., "Mathematical Analysis of U-shaped Components in a Vibratory Bowl Feeder". International Journal of Electronics, Electrical and Computational Systems, Vol. 5, Issue 4, pp. 91-99, April, 2016.

[6] Bhagat, S., Pandey, T., Garg, V., Khanna, P., "Design, Fabrication and Analysis of Vibratory Feeder". IJRMET, Vol. 4, Issue 1, pp. 73-75, November 2013 - April 2014.

[7] Bhagat, S., Pandey, T., Garg, V., Khanna, P., "Mathematical Analysis of Vibratory Bowl Feeder". International Journal of Latest Trends in Engineering and Technology, Vol 4, Issue 1, pp. 315-324, 2014.

[8] Jindal, U., Jain, S., Piyush, Khanna, P., "Graphical Analysis of a Vibratory Bowl Feeder for Clip shaped Components". IJISET - International Journal of Innovative Science, Engineering \& Technology, Vol. 4 Issue 2, pp. 279-283, February 2017.

[9] Jain, S., Jindal, U., Piyush,Khanna, P., "Mathematical Analysis of Vibratory Bowl Feeder for Clip Shaped Components". Journal of Production Engineering, Vol.20, pp. 122-126, 2017.

[10] Jain, A., Bansal, P., Khanna, P., "Application of Taguchi Technique to Optimize the Performance of A Vibratory Bowl Feeder".Global Journal on Innovation, Opportunities and Challenges in AAI and Machine Learning, Vol. 1, pp. 13-18, Issue 1,2017. 